UNIVERSIDADE DE SÃO PAULO

FACULDADE DE FILOSOFIA, CIÊNCIAS E LETRAS DE RIBEIRÃO PRETO PROGRAMA DE PÓS-GRADUAÇÃO EM ENTOMOLOGIA

\title{
Efeito de vespas galhadoras (Hymenoptera: Chalcidoidea) na duração da receptividade floral de Ficus citrifolia (Moraceae)
}

\author{
Pâmela Costa Adorno da Silva
}

Dissertação apresentada à Faculdade de Filosofia, Ciências e Letras de Ribeirão Preto da USP, como parte das exigências para obtenção do título de Mestre em Ciências, Área: Entomologia.

Ribeirão Preto - SP 
UNIVERSIDADE DE SÃO PAULO

FACULDADE DE FILOSOFIA, CIÊNCIAS E LETRAS DE RIBEIRÃO PRETO PROGRAMA DE PÓS-GRADUAÇÃO EM ENTOMOLOGIA

\title{
Efeito de vespas galhadoras (Hymenoptera: Chalcidoidea) na duração da receptividade floral de Ficus citrifolia (Moraceae)
}

\author{
Pâmela Costa Adorno da Silva \\ Orientador: Prof. Dr. Rodrigo Augusto Santinelo Pereira \\ Dissertação apresentada à Faculdade de Filosofia, Ciências e \\ Letras de Ribeirão Preto da USP, como parte das \\ exigências para obtenção do título de Mestre em \\ Ciências, Área: Entomologia.
}

Ribeirão Preto - SP

2009 
Silva, Pamela Costa Adorno

Efeito de vespas galhadoras (Hymenoptera: Chalcidoidea) na duração da receptividade floral de Ficus citrifolia (Moraceae). Ribeirão Preto, 2009.

Dissertação de Mestrado, apresentada à Faculdade de Filosofia, Ciências e Letras de Ribeirão Preto/USP. Área de concentração: Entomologia

Orientador: Pereira, Rodrigo Augusto Santinelo.

1. Agaonidae. 2.Idarnes. 3. Interação inseto-planta. 4. Polinização. 
Aos meus pais,

que sempre incentivaram meus estudos. 


\section{Agradecimentos}

Ao programa de Pós-graduação em Entomologia da Faculdade de Filosofia Ciências e Letras de Ribeirão Preto;

Ao CNPq e FAPESP (2007/01316-0) pela bolsa de mestrado e à FAPESP pelo auxílio financeiro (04/10299-4);

Ao Prof. Dr. Rodrigo Augusto Santinelo Pereira, pela orientação, pelas discussões e correções, e pela paciência e apoio nos momentos mais difíceis;

À Profa. Dra. Maria Helena Goldman pelo empréstimo do reagente químico;

Aos amigos do laboratório de Ecologia Vegetal: Ana Cláudia, Anayra, Fernando, Larissa, Luciano, Ludmila, Luis, Mariana, Michele, Monise e Sérgio, pela amizade e troca de artigos;

À Larissa, por ter sido a primeira a me mostrar a beleza da interação figo-vespa de figo, além de me ensinar a montar os experimentos em campo, e a coletar e identificar as vespas;

Ao Luciano pelo auxílio no carregamento e montagem dos andaimes em campo;

À Ludmila, Mariana, Michele, Sérgio e Vanessa pela ajuda na montagem e andamento de alguns dos experimentos em campo;

À Ana Cláudia, Anayra, Monise e Michele, pelos dados de fenologia;

Aos meus pais Maria Candida e Osvaldo, pelo amor, apoio e compreensão;

À Mariana, por toda a ajuda na análise dos dados e na confecção dos gráficos;

À Vanessa, pelo sorriso que encantou tanto as minhas manhãs;

À Cláudia por estar sempre comigo, na alegria e no desespero;

À Juliana, Fernanda e Pablo, pelo carinho, alegria, companheirismo e, principalmente, por me proporcionarem uma família postiça tão maravilhosa;

À Gisele e Emilena, que só aparecerem de vez em quando, mas fazem cada minuto valer a pena;

Ao Simeão e à Ângela, que mesmo longe, continuam bem perto;

À Maria Izabel e Rafaela, por me ouvirem, aconselharem e acalmarem tantas vezes;

Ao Alexandre, por ter sido uma surpresa tão boa.

Este trabalho é vinculado ao CEEFLORUSP (Centro de Estudos e Extensão Florestal da USP-RP). 
Resumd Abstract.........................................................................................................

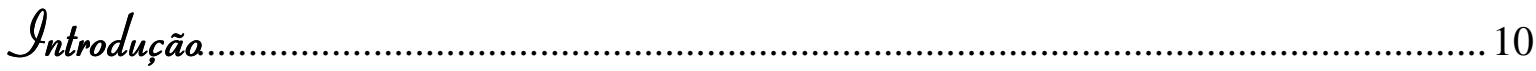

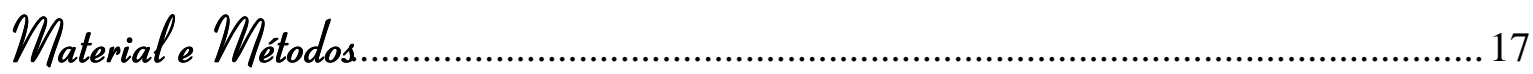

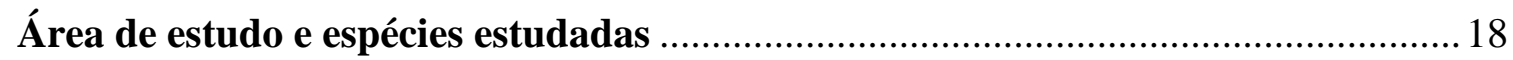

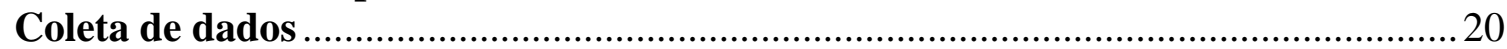

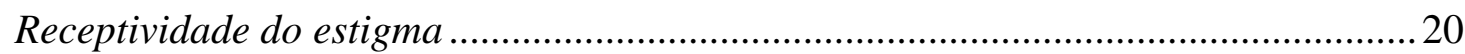

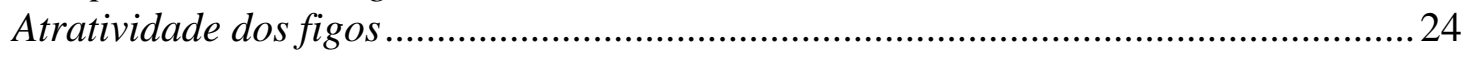

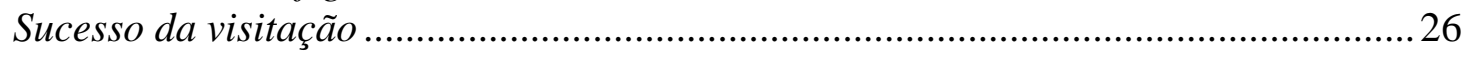

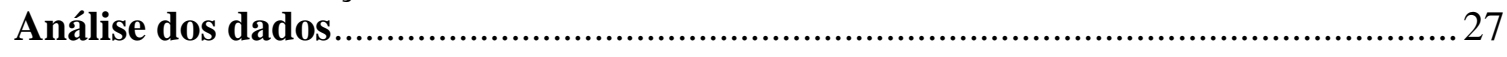

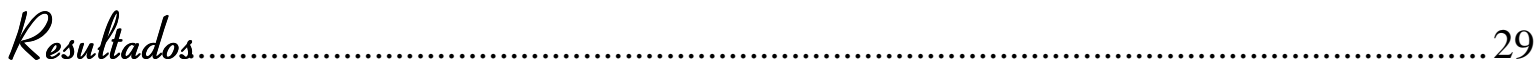

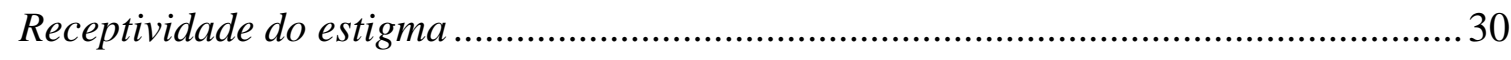

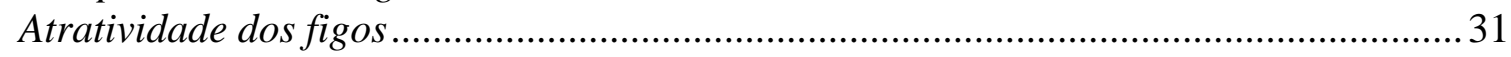

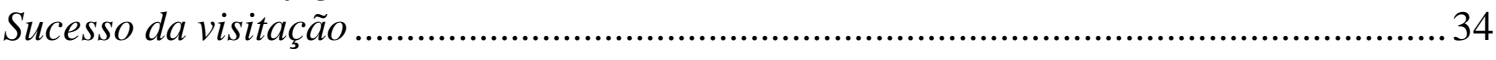

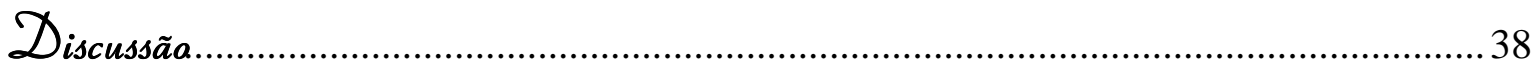

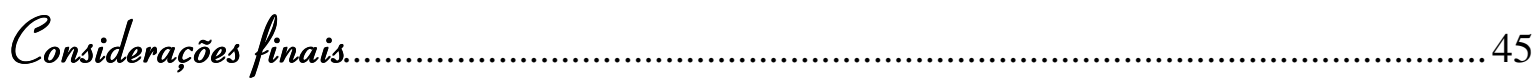

Referências Bibliográficas.............................................................................................. 49 
Resumol Abstract

7 
O sucesso reprodutivo das figueiras, e a consequente manutenção do mutualismo Ficus - vespas de figo, depende do sucesso na polinização das flores pistiladas (produção de frutos) e do desenvolvimento de vespas polinizadoras em alguns ovários galhados (produção de vespas vetoras de pólen). No entanto, o período de receptividade das flores pistiladas para a polinização e oviposição pelas vespas polinizadoras de Ficus é curta, em relação à duração total do desenvolvimento do figo. A pequena janela temporal de receptividade pode ser um fator limitante na estabilidade do mutualismo, uma vez que o sucesso reprodutivo da planta será nulo se os figos não forem visitados por vespas polinizadoras durante o período de receptividade. O presente trabalho avaliou o papel das vespas não-polinizadoras galhadoras (Idarnes grupo flavicollis) durante o período de polinização Ficus citrifolia. Especificamente avaliou-se se as vespas galhadoras interferem (1) na atratividade do figo às vespas polinizadoras, (2) na receptividade do estigma e (3) no sucesso das vespas polinizadoras (produção de frutos e prole de vespas polinizadoras). $\mathrm{O}$ estudo experimental foi realizado no campus da USP - Ribeirão Preto ( $21^{\circ} 10^{\prime}$ S; $\left.47^{\circ} 48^{\prime} \mathrm{W}\right)$, durante os meses de 02/2008 e 07/2009. Foi observado que os períodos de receptividade do estigma e de atratividade do figo duraram cerca de uma semana e não sofreram efeito da presença das vespas galhadoras. No entanto, o sucesso reprodutivo da planta foi afetado em situações de alta infestação das vespas não-polinizadoras, devido ao fechamento precoce do ostíolo causado pelo crescimento das galhas dessas vespas.

Palavras-chave: Agaonidae, Idarnes, Interação inseto-planta, Polinização. 
The breeding success of Ficus trees and the maintenance of their mutualistic fig wasps depend on the successful pollination of pistilate flowers (seed production) and on the development of pollinating wasps in some galled ovaries (production of pollen vectors). The period during which pistilate flowers are receptive for pollination and oviposition is short compared to the total length of fig development. This narrow temporal window may be limiting to the stability of the mutualism, since the reproductive success of the plant will be null if wasps fail to find receptive trees. We investigated the role of the non-pollinating galler wasps (Idarnes group flavicollis) on the pollination period of Ficus citrifolia figs. Specifically, we tested if galler wasps interfere on (1) fig attraction for pollinating fig wasps, (2) length of stigma receptivity and (3) pollinating success (seed and pollinator offspring production). The study was carried out at the campus of University of São Paulo in Ribeirão Preto ( $\left.21^{\circ} 10^{\prime} \mathrm{S}, 47^{\circ} 48^{\prime} \mathrm{W}\right)$ between february/2008 and march/2009. The periods of stigma receptivity and fig attractiveness lasted about one week and were not affected by the presence of galling non-pollinating fig wasps. However, the early ostiole closure caused by the growth of non-pollinating wasps' galls may affect the plant reproductive success in high levels of infestation by these wasps.

Key words: Agaonidae, Idarnes, Plant-insect interaction, Polination. 
Introdução 
Mutualismos são interações interespecíficas que resultam em benefício a todas as espécies envolvidas (Begon et al., 1996). Entre as associações planta-inseto, Ficus (Moraceae) e suas vespas polinizadoras (Hymenoptera: Chalcidoidea) constituem um dos exemplos mais extremos de mutualismo obrigatório (Weiblen, 2002). Nessa associação, as vespas polinizam as flores femininas e utilizam algumas delas para depositar seus ovos e desenvolver sua prole (Weiblen, 2002). As figueiras também são exploradas por espécies de vespas não-polinizadoras, em geral da superfamília Chalcidoidea, consideradas parasitas do mutualismo. Algumas espécies dessas vespas desenvolvem-se em flores femininas e outras são parasitóides das espécies fitófagas (Yu, 2001), sem realizar serviços de polinização.

Ficus é o maior gênero da família Moraceae, constituído por cerca de 750 espécies distribuídas no Velho e Novo Mundo, nas regiões tropicais, subtropicais e algumas regiões temperadas e é dividido em quatro subgêneros e 18 seções (Berg, 1989). Na América ocorrem aproximadamente 140 espécies, pertencentes aos subgêneros Urostigma e Pharmacosycea (Berg, 1989). No Brasil, são conhecidas 59 espécies nativas, cinco pertencentes ao subgênero Pharmacosycea e 54 ao subgênero Urostigma. Além dessas, ocorrem trinta espécies exóticas, dos subgêneros Ficus, Sycomorus e Urostigma (Carauta, 1989).

Todas as espécies de Ficus apresentam inflorescência do tipo sicônio (ou figo), o qual é um receptáculo fechado com as flores inseridas internamente (Verkerke, 1989). As flores femininas se desenvolvem em frutos do tipo aquênio, que apresentam pericarpo duro envolvendo uma única semente (Verkerke, 1989). A produção de aquênios representa a 
função feminina da planta, enquanto a dispersão de pólen pelas fêmeas de vespas polinizadoras constitui a função masculina da planta. A produção de sicônios é geralmente sincronizada em uma figueira, mas assincrônica entre diferentes árvores (Pereira et al., 2007).

Galil \& Eisikowitch (1968) dividiram o ciclo de desenvolvimento do sicônio e das vespas de figo em cinco fases (Tabela 1 - Figura 1). Nas espécies monóicas, esse ciclo pode ser resumido da seguinte forma: as fêmeas de vespas polinizadoras, fecundadas e carregadas de pólen, são atraídas por substâncias voláteis liberadas pelos sicônios receptivos (Hossaert-McKey et al., 1994). As vespas fêmeas (fundadoras) adentram a inflorescência através de uma abertura denominada ostíolo, geralmente perdendo as antenas e as asas nesse processo, e realizam a polinização das flores femininas, ainda utilizando-se dos ovários de algumas dessas flores polinizadas para depositar seus ovos. As flores que recebem ovos desenvolvem-se em galhas, nas quais a prole de vespas se desenvolve no lugar dos frutos. Durante a fase de desenvolvimento da prole de vespas, as larvas se alimentam do endosperma e do embrião formados pela fertilização (Verkerke, 1989; Jansen, 2009).

Algumas semanas mais tarde (aproximadamente de quatro a seis semanas), próximo ao final do ciclo de desenvolvimento do sicônio, as flores masculinas amadurecem e a prole de vespas completa seu desenvolvimento. Os machos são os primeiros a emergir e, logo após a emergência, localizam as fêmeas, que ainda se encontram em suas galhas, e copulam com elas. Após a cópula, os machos de algumas espécies utilizam suas mandíbulas para abrir um pequeno orifício na parede da inflorescência, por onde as vespas fêmeas sairão. As fêmeas fecundadas, então, emergem, coletam o pólen (em algumas espécies, as fêmeas não coletam o pólen, transportando-o passivamente sobre o corpo) e abandonam o sicônio em busca de uma árvore com inflorescências receptivas (Bronstein, 1992). Depois da saída das 
vespas, os sicônios completam seu amadurecimento, tornando-se atrativos para várias espécies de vertebrados frugívoros que atuam como dispersores (Shanahan et al., 2001).

Tabela 1: Fases do desenvolvimento do sicônio e das vespas polinizadoras de espécies monoicas de Ficus, segundo Galil \& Eisikowitch (1968).

\begin{tabular}{cc}
\hline Fase & Descrição \\
\hline A (pré-feminina) & Flores femininas do sicônio imaturas \\
B (feminina) & Figo receptivo. Liberação de voláteis e atração de fundadoras \\
C (interfloral) & Período de desenvolvimento da prole de vespas e dos frutos \\
D (masculina) & Emergência da prole de vespas e maturação das flores \\
E (pós-floral) & A prole de vespas se dispersa e o figo amadurece \\
\hline
\end{tabular}

A complexidade do mutualismo Ficus - vespas de figo aumenta pela ocorrência das vespas não-polinizadoras (Figura 1). Essas vespas utilizam o figo para desenvolver suas proles, mas não realizam polinização, uma vez que depositam seus ovos pelo lado externo, inserindo seus ovipositores através da parede do figo (Weiblen, 2002; Yu, 2001). Em geral, o comprimento dos ovipositores das vespas não-polinizadoras é positivamente correlacionado à espessura da parede do figo (Kerdelhué \& Rasplus, 1996; Zhen et al., 2005).

A biologia dessas vespas é variada, podendo ser galhadoras, inquilinas (cleptoparasitas) ou parasitoides (Abdurahiman \& Joseph, 1978; Weiblen, 2002). As parasitas galhadoras são fitófagas e capazes de induzir galhas nas flores femininas do figo. A indução de galhas (proliferação anormal do tecido nucelar) pode estar relacionada a uma secreção ácida liberada no momento da oviposição por glândulas associadas ao aparelho 
reprodutor, o que é corroborado pelo fato de essas glândulas serem observadas somente em espécies galhadoras (Abdurahiman \& Joseph, 1978). Essas vespas colonizam o figo no mesmo período em que as polinizadoras, podendo potencialmente fazer uso dos mesmos voláteis atrativos que as primeiras (Ware \& Compton, 1994).

As vespas inquilinas também são fitófagas, mas não induzem a formação de galhas (ausência de glândulas ácidas). Elas colonizam o figo alguns dias após as espécies galhadoras, ovipõem em galhas induzidas por algumas dessas espécies e se alimentam do tecido vegetal, matando a larva da espécie galhadora por inanição. As espécies parasitoides, por sua vez, desenvolvem suas proles parasitando as larvas de espécies fitófagas e são, geralmente, as últimas a colonizar o figo. A emergência sincronizada de todas as espécies, independente da sequência de oviposição, pode estar relacionada a diferentes taxas de crescimento larval entre as espécies (Kerdelhué \& Rasplus, 1996).

Com o exposto acima, nota-se que um ajuste fino entre os ciclos de desenvolvimento dos figos e das vespas associadas é necessário para a manutenção dessas interações. O sucesso reprodutivo das figueiras, e a consequente manutenção do mutualismo dependem do sucesso na polinização de flores femininas (produção de frutos) e do desenvolvimento de vespas polinizadoras em alguns ovários galhados (produção de vespas vetoras de pólen). No entanto, o período de receptividade das flores femininas para a polinização e oviposição pelas vespas polinizadoras de Ficus é curta, em relação à duração total do desenvolvimento do figo (Weiblen, 2002). A pequena janela temporal de receptividade pode ser um fator limitante na estabilidade do mutualismo, uma vez que o sucesso reprodutivo da planta será nulo se os figos não forem visitados por vespas polinizadoras durante o período de receptividade (Kjellberg et al., 2005). 


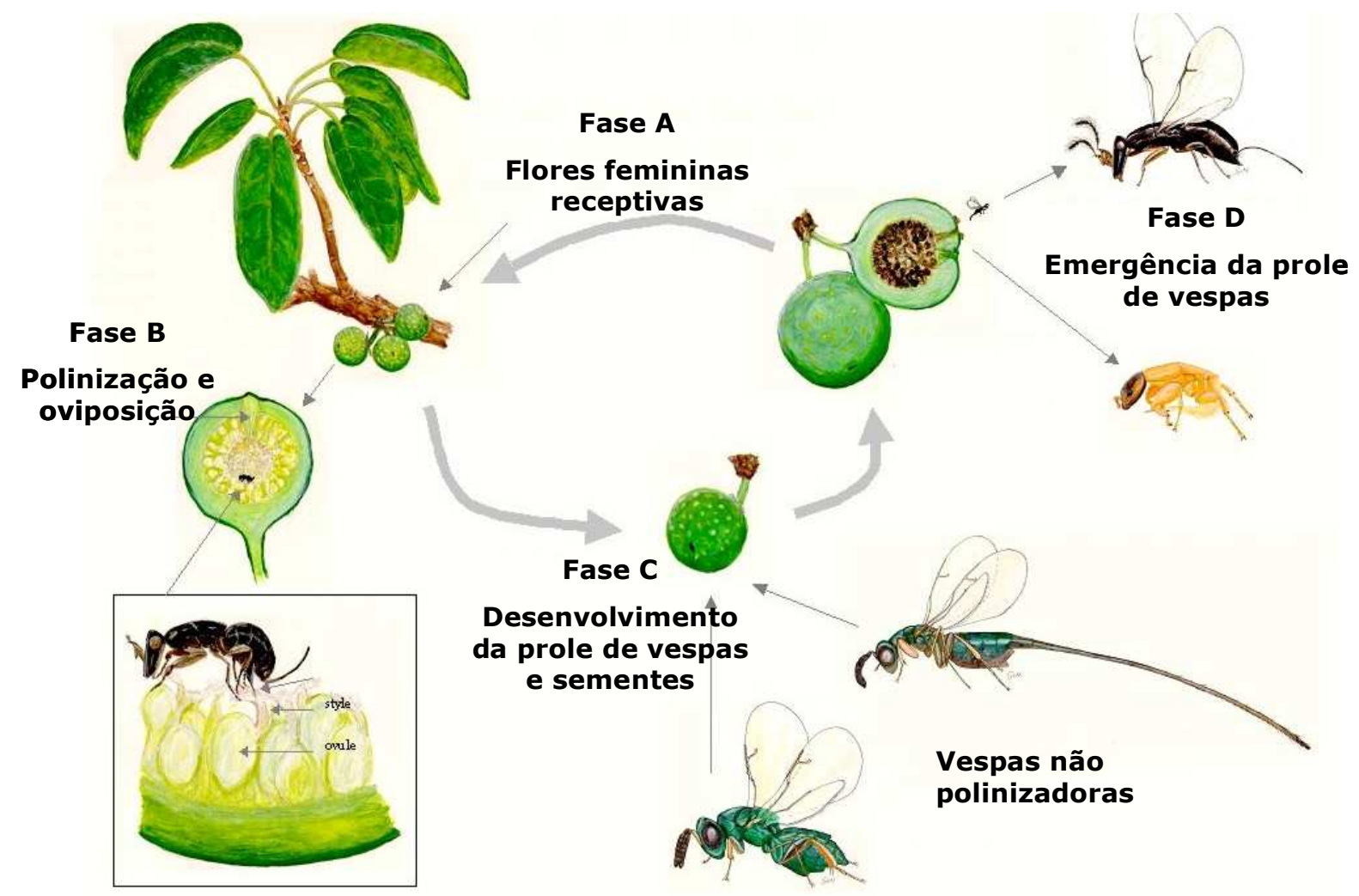

Figura 1: Ciclo de desenvolvimento dos sicônios e vespas de figo em espécies monóicas de Ficus.

Modificado de Simon van Noort (www.figweb.org).

Khadari et al. (1995) demonstraram experimentalmente que a atratividade das flores femininas de Ficus se estende a até um mês na ausência de polinização. Em situações normais de visitação por vespas polinizadoras, o figo se torna não-atrativo em aproximadamente dois dias após ser penetrado pela polinizadora (Khadari et al., 1995), pois, pouco depois que a polinizadora entra, os compostos voláteis atrativos deixam de ser produzidos (Ware \& Compton, 1994).

Quando comparada a outras plantas zoofílicas, as figueiras apresentam baixo custo energético de espera por polinizadores, uma vez que os figos realizam fotossíntese, cobrindo parte dos gastos por sua manutenção. É possível que o baixo custo da manutenção dos figos tenha possibilitado o prolongamento da receptividade dos mesmos, o que pode ter sido selecionado evolutivamente por aumentar o sucesso reprodutivo da planta, ou seja, 
aumentando as chances de polinização sem custos extras. No entanto, Khadari et al. (1995) não avaliaram se a colonização dos figos por vespas não-polinizadoras fitófagas, que ovipõem nas flores femininas um pouco antes ou no mesmo período que as vespas polinizadoras, interferem na receptividade das flores femininas (como ocorre com a colonização pelas polinizadoras). A modificação da duração da receptividade pelas vespas não-polinizadoras potencialmente afetaria o sucesso reprodutivo da planta. Nesse sentido, a figueira teria seu sucesso reprodutivo diminuído se a colonização de seus figos por vespas não-polinizadoras fitófagas interrompesse a receptividade das flores femininas antes que a polinização ocorresse.

A literatura atual conta com estudos que apresentam o período de atratividade e o sucesso reprodutivo de algumas espécies de figueiras, mas que não tratam do período de receptividade (algumas vezes usado como sinônimo de atratividade). Dessa forma, o objetivo deste estudo foi avaliar se a presença das vespas não-polinizadoras galhadoras Idarnes grupo flavicollis, interfere no mutualismo de Ficus citrifolia e sua vespa polinizadora Pegoscapus sp. Mais especificamente, buscou-se:

a) Avaliar a duração da receptividade floral de Ficus citrifolia na ausência e na presença da vespa não-polinizadora Idarnes grupo flavicollis;

b) Avaliar a duração do período de atratividade dos figos de Ficus citrifolia na ausência e na presença da vespa não-polinizadora Idarnes grupo flavicollis;

c) Avaliar o sucesso reprodutivo de Ficus citrifolia e Pegoscapus sp. ao longo do período de receptividade dos figos, na ausência e na presença da vespa nãopolinizadora Idarnes grupo flavicollis. 
Material e Métodos 


\section{Área de estudo e espécies estudadas}

O trabalho foi realizado em áreas urbanizadas (jardins e gramados) do campus da USP - Ribeirão Preto $\left(21^{\circ} 10^{\prime} \mathrm{S} ; 4^{\circ} 48^{\prime} \mathrm{W}\right)$. Ficus citrifolia (Figura 2) é uma espécie de ampla distribuição geográfica (Pereira, 2002; referido como F. eximia) e se desenvolve bem em ambientes perturbados. Ficus citrifolia é a espécie mais abundante de Ficus na área de estudo, desenvolvendo-se isoladamente sobre o solo ou como hemiepífita sobre outras espécies arbóreas e construções (Cerezini et al. 2005).
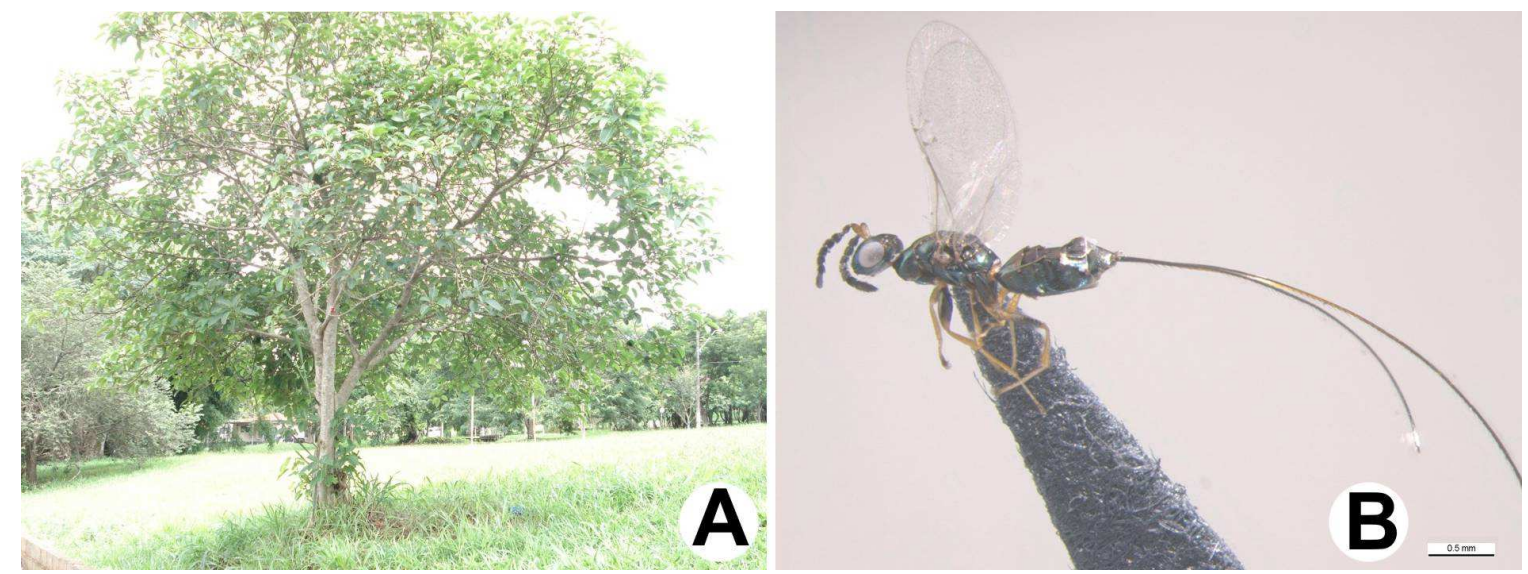

Figura 2. (A) Ficus citrifolia no campus da USP de Ribeirão Preto; (B) Fêmea de Idarnes grupo flavicollis. .

No Brasil, Ficus citrifolia é polinizado por Pegoscapus tonduzi e associado a outras 14 espécies de vespas não-polinizadoras (Pereira et al. 2000). Dentre as espécies nãopolinizadoras, o gênero Idarnes é o melhor representado, com três espécies com machos ápteros [dois do grupo carme (Idarnes sp.1 e sp.2) e um do grupo flavicollis (sp.3) (Figura 
2)] e duas espécies com machos alados (grupo incerta). As demais espécies de outros gêneros associadas a $F$. citrifolia são apresentadas na Tabela 2.

Os experimentos de receptividade foram realizados três vezes, em três árvores diferentes e em meses distintos (fevereiro/2008, março/2008 e junho/2009). Para atratividade, também foram realizados três experimentos (fevereiro/2009, março/2009 e junho/2009), e para o sucesso da visitação foram realizados dois experimentos (março/2009 e julho/2009). Foram realizados os dois tratamentos (com e sem vespa Idarnes) concomitantemente em cada árvore, a fim de evitar diferenças nos resultados devido a possíveis variações específicas entre as árvores, ou em decorrência de mudanças climáticas.

Tabela 2: Categorias superiores, número de espécies e características morfológicas de gêneros associados a Ficus citrifolia. Ribeirão Preto/SP. Modificado de Pereira et al. 2000.

\begin{tabular}{|c|c|c|c|c|}
\hline Família & Subfamília & Gênero & Espécies & Machos \\
\hline & Agaoninae & Pegoscapus Cameron & 1 & Ápteros \\
\hline $\begin{array}{c}\text { Agaonidae } \\
\text { (sensu Bouček 1993) }\end{array}$ & Sycophaginae & $\begin{array}{c}\text { Idarnes grupo carme } \\
\text { Idarnes grupo flavicollis } \\
\text { Idarnes grupo incerta }\end{array}$ & $\begin{array}{l}3 \\
1 \\
2\end{array}$ & $\begin{array}{l}\text { Ápteros } \\
\text { Ápteros } \\
\text { Alados }\end{array}$ \\
\hline $\begin{array}{c}\text { Pteromalidae } \\
\text { (sensu Rasplus et al. 1998) }\end{array}$ & $?$ & $\begin{array}{c}\text { Aepocerus Mayr } \\
\text { Heterandrium Mayr }\end{array}$ & $\begin{array}{l}1 \\
2\end{array}$ & $\begin{array}{l}\text { Alados } \\
\text { Ambos }\end{array}$ \\
\hline Eurytomidae & - & Eurytoma Illiger & 2 & Alados \\
\hline Torymidae & - & $\begin{array}{l}\text { Physothorax Mayr } \\
\text { Torymus Dalman }\end{array}$ & $\begin{array}{l}2 \\
1\end{array}$ & $\begin{array}{c}\text { Alados } \\
\text { Ápteros, alados e } \\
\text { braquípteros }\end{array}$ \\
\hline
\end{tabular}




\section{Coleta de dados}

Receptividade do estigma

A receptividade do estigma foi avaliada em figos não polinizados, a cada dois dias a partir do início da fase receptiva (primeiro dia de receptividade dos figos). Quarenta figos, em aproximadamente cinco ramos, foram etiquetados e ensacados com tecidos "voil" para evitar o acesso de qualquer vespa de figo (Figura 3A e B). Cada ramo ensacado foi etiquetado de acordo com o tratamento experimental ("Controle" ou "Idarnes" (com Idarnes)) (Figura 3C e D). A partir do primeiro dia da fase receptiva, dois figos (de ramos distintos) foram coletados e levados ao laboratório para análise da receptividade dos estigmas. A receptividade do estigma foi avaliada por meio do teste indicador de esterase proposto por Dafni \& Maués (1998). Este teste é considerado confiável para detectar a alta atividade de enzimas característica de estigmas receptivos (Dafni \& Maués, 1998).

Os figos coletados foram cortados ao meio e em cada uma das metades foi colocado um pequeno pedaço de papel reagente (Peroxitesmo KO), previamente umedecido em água destilada, diretamente sobre as flores. O manuseio do papel foi feito com pinça, tomando sempre o cuidado de não expor o papel às extremidades cortadas ou ao contato com qualquer outro material na bancada. A pinça foi lavada com álcool e água destilada após cada procedimento, evitando uma possível transferência de enzimas de um tratamento para o outro. Esses procedimentos visaram evitar a ocorrência de falsos positivos por contaminação de material. 

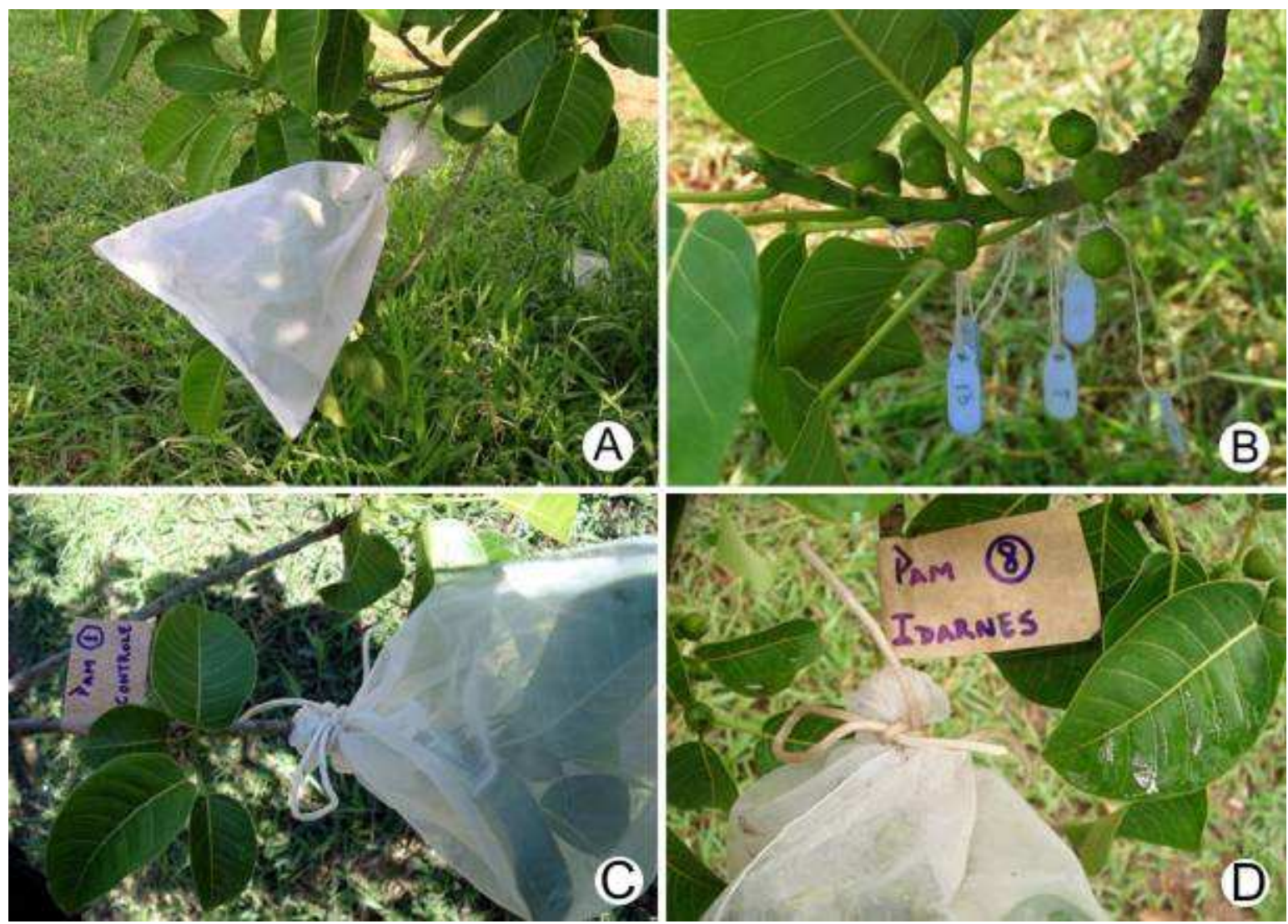

Figura 3. (A) Ramo ensacado com tecido "voil"; (B) figos etiquetados para identificação individual; (C) Ramo com etiqueta de identificação "Controle" (sem Idarnes); (D) Ramo com etiqueta de identificação "Idarnes" (com Idarnes).

O estigma foi considerado receptivo quando o papel reagente se tornava azul escuro em até 10 segundos após o contato com as flores, e considerado não receptivo quando o papel permanecia branco ou se tornava azul claro num período maior que dez segundos após a exposição às flores (Figura 4). No primeiro dia em que a não-receptividade foi observada, foram coletados mais três figos de diferentes ramos, os quais receberam o mesmo tratamento para confirmar o resultado negativo. 


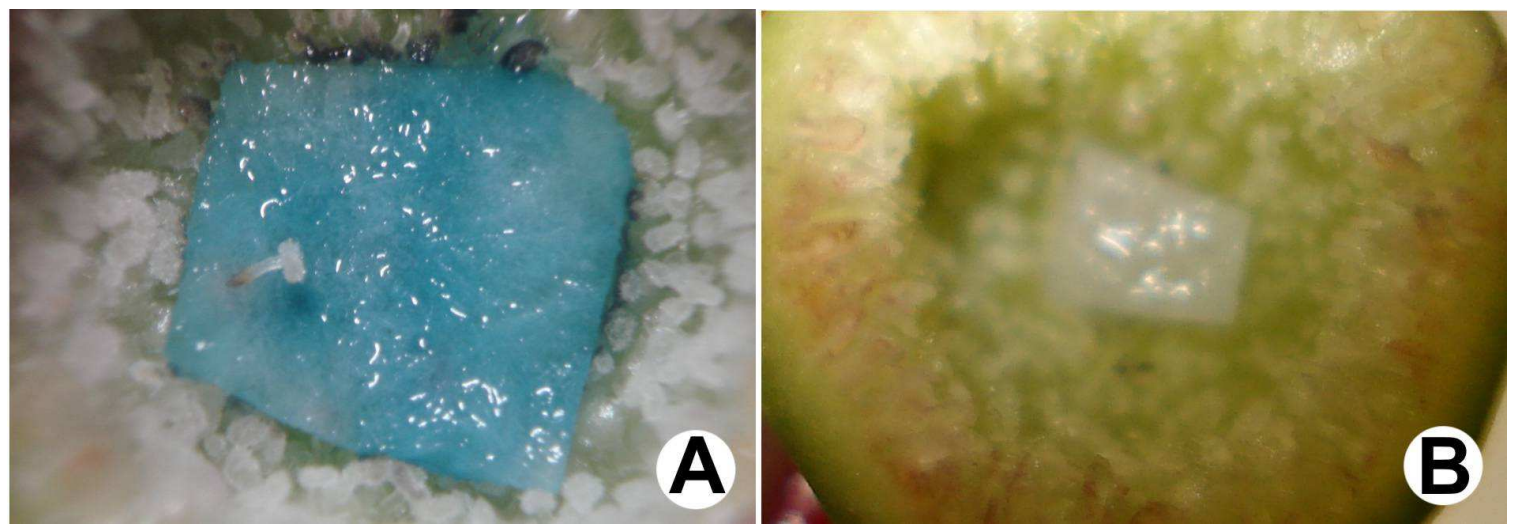

Figura 4. (A) figo com papel reagente corado (receptivo); (B) figo com papel reagente sem corar (não-receptivo).

A avaliação da receptividade do estigma em figos colonizados por vespas galhadoras foi realizada de forma semelhante à descrita no item anterior. A diferença consistiu em permitir a colonização dos figos no início da fase receptiva (primeiro dia de receptividade) por vespas Idarnes grupo flavicollis.

As fêmeas de Idarnes grupo flavicollis utilizadas nos experimentos foram obtidas de sicônios de outras árvores (na fase D). Os sicônios na fase masculina foram colhidos e mantidos em recipientes plásticos de $50 \mathrm{ml}$ fechados até a emergência das vespas (Figura 5A-B). As vespas foram separadas das demais espécies e colocadas, duas a duas em sacos pequenos de "voil" (Figura 5C). 


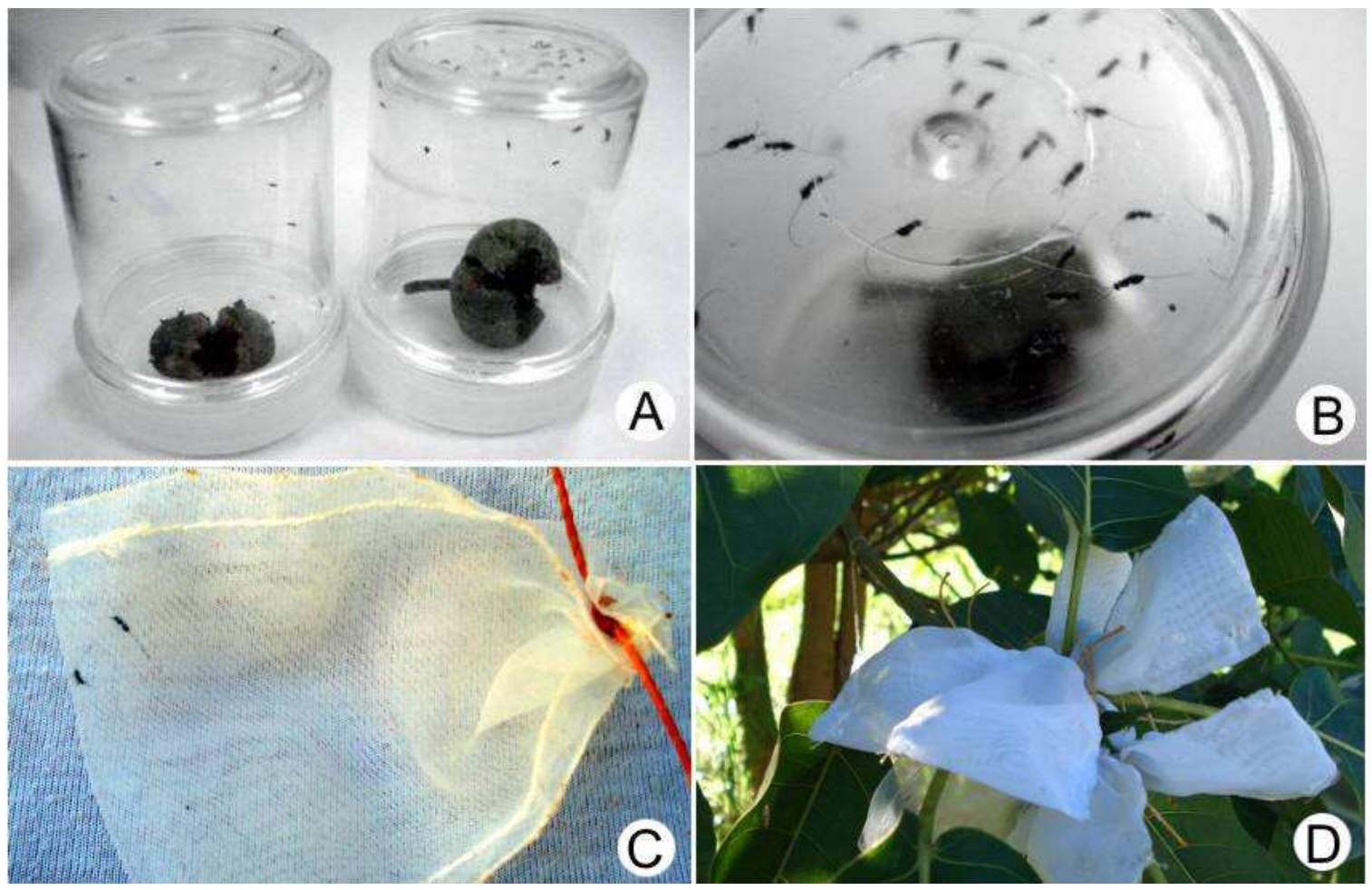

Figura 5. (A) emergência das vespas em recipientes plásticos fechados;

(B) vespas já emergidas; (C) saquinho de "voil” individual com duas fêmeas de Idarnes grupo (flavicollis) e (D) figos ensacados individualmente.

Cada saquinho contendo duas vespas fêmeas de Idarnes grupo flavicollis foi utilizado para ensacar individualmente cada figo para permitir a oviposição das mesmas (Figura 5D). Após 24 horas, os sacos individuais foram removidos e o experimento foi conduzido da forma descrita para o tratamento sem as vespas galhadoras. Cada ramo ensacado recebeu uma etiqueta de identificação com um número e o tipo de tratamento ao qual os figos seriam submetidos (Figura 3D).

Os dois tratamentos (receptividade do estigma na ausência e presença de Idarnes) foram realizados simultaneamente em uma mesma árvore e repetidos em três árvores distintas, em períodos distintos do ano (fevereiro/2008, março/2008 e junho/2009), assegurando que os resultados obtidos para cada tratamento não sofressem influencia da diferença das árvores ou da variação climática. 


\section{Atratividade dos figos}

A atratividade dos figos foi avaliada a cada dois dias, a partir do primeiro dia em que os figos se mostraram atrativos, determinado pela chegada de vespas polinizadoras à árvore. A atratividade foi avaliada pelo comportamento das vespas polinizadoras quando em contato com figos. Os figos foram considerados atrativos quando as vespas polinizadoras apresentaram comportamento de tentativa de entrada e considerados não atrativos quando a vespa gastava mais de cinco minutos sobre o figo, sem apresentar o comportamento de entrada.

O comportamento de entrada no figo foi descrito segundo três comportamentos descritos por Kandari et al. (1995), sendo:

1. A vespa anda ao redor do sicônio tocando sua superfície continuamente com os segmentos distais da antena; quando a vespa encontra o ostíolo, tenta entrar empurrando suas antenas sob as brácteas.

2. A vespa dispende certo tempo (inferior a cinco minutos) caminhando sobre o figo, mas não apresenta tentativa de entrada; essa situação foi observada antes do início e ao final do período atrativo.

3. A vespa toca uma vez a superfície do sicônio, levanta as antenas e rapidamente caminha ou voa para outro lugar.

Apenas o primeiro comportamento é considerado indício de que o figo está atrativo. A não-tentativa de entrada pelas vespas caracterizaria a ausência de atratividade do figo.

Cerca de 30 figos em cinco ramos (seis figos por ramo) na fase pré-feminina (fase A) foram etiquetados e ensacados com tecidos "voil" (Figura 3) para evitar o acesso de qualquer vespa de figo. Cada ramo ensacado recebeu uma etiqueta de identificação com um número e o tratamento ao qual os figos seriam submetidos (Figura 3). A cada dois dias, fêmeas polinizadoras recém-emergidas, obtidas de outras árvores de F. citrifolia na fase D, 
foram usadas para o teste da atratividade. O saco de "voil" foi removido temporariamente e pequenos sacos do mesmo material foram colocados individualmente nos figos, para evitar que vespas polinizadoras colonizassem naturalmente os figos experimentais.

Para avaliar cada figo do ramo, o saco menor foi removido e uma vespa polinizadora foi posicionada, com o auxílio de um pincel fino, próximo ao ostíolo do figo. Foi observado o comportamento da vespa de tentativa (ou não) de penetrar o figo. Em caso positivo, a vespa era removida com o pincel antes que penetrasse o figo. Em caso negativo, as tentativas foram repetidas outras duas vezes com vespas diferentes. Em caso de insucesso nas três tentativas, o figo era considerado não-atrativo. Durante todas as avaliações sempre se tomou cuidado de não deixar descobertos (sem os sacos pequenos) os figos experimentais, para se assegurar que nenhuma vespa polinizadora os colonizasse naturalmente. Após as avaliações, os sacos pequenos eram removidos e o ramo novamente ensacado.

A avaliação da atratividade dos figos colonizados por vespas galhadoras foi realizada de forma semelhante à descrita no item anterior. A diferença consistiu em permitir a colonização dos figos no primeiro dia de atratividade por vespas Idarnes grupo flavicollis. Para tal, no primeiro dia de atratividade, duas vespas fêmeas de Idarnes foram introduzidas em cada figo ensacado individualmente (com sacos pequenos de "voil") para permitir a oviposição (Figura 5D). Após 24 horas os sacos individuais foram removidos e o experimento foi conduzido da forma descrita para o tratamento anterior. Cada ramo ensacado recebeu uma etiqueta de identificação com um número e o tratamento ao qual os figos foram submetidos (Figura 3D).

Os dois tratamentos (atratividade do figo na ausência e presença de Idarnes) foram realizados simultaneamente em uma mesma árvore e repetidos em três árvores distintas, em períodos distintos do ano (fevereiro/2009, março/2009 e junho/2009), assegurando que os 
resultados obtidos para cada tratamento não sofressem influência da diferença das árvores ou da variação climática.

\section{Sucesso da visitação}

O sucesso da visitação (produção de frutos e desenvolvimento da prole) pelas vespas polinizadoras foi avaliado a partir do primeiro dia de receptividade dos figos. Cerca de 10 ramos foram etiquetados e ensacados com tecido "voil" (Figura 3A-B) na fase pré-feminina (fase A) para evitar o acesso de qualquer vespa de figo. Cada ramo ensacado recebeu uma etiqueta de identificação com um número e tratamento (com e sem vespas galhadoras) ao qual os figos foram submetidos (Figura 3C). A cada dois dias após o início da receptividade, quatro a seis figos de um mesmo ramo foram oferecidos às vespas polinizadoras (uma vespa por figo). As vespas polinizadoras utilizadas nos experimentos foram obtidas de sicônios de outras árvores na fase D. Após as vespas penetrarem os figos, os ramos foram mantidos ensacados até o final do desenvolvimento das vespas (fase D). Ao atingirem a fase $\mathrm{D}$, os figos foram coletados e individualizados em frascos plásticos de 50mL para emergência das vespas. Depois da emergência, o figo foi dissecado para quantificação das sementes e vespas produzidas e das galhas onde ocorreu mortalidade larval (denominadas "bexigas", por apresentarem-se vazias). As vespas emergidas foram preservadas em recipientes plásticos de $2 \mathrm{~mL}$ com álcool (70\%), sendo que cada recipiente individual apresenta o conteúdo de apenas um figo triado (Figura 6).

A avaliação do sucesso da visitação em figos colonizados por vespas galhadoras foi realizada de forma semelhante à descrita acima. A diferença consistiu em permitir a colonização dos figos no primeiro dia de receptividade por vespas Idarnes, conforme descrito no item anterior. O experimento foi conduzido da forma descrita acima, com adição da quantificação, ao final, também da prole de Idarnes. 
Como a infestação das vespas galhadoras foi baixa, na repetição do experimento de sucesso modificamos um pouco a metodologia em relação à original. Além da exposição às duas vespas galhadoras no primeiro dia de receptividade, cada figo foi exposto a mais três vespas no segundo dia, ou seja, houve um aumento na infestação por parasitas.

Os dois tratamentos (sucesso da visitação na ausência e presença de Idarnes) foram realizados simultaneamente em uma mesma árvore e repetidos em duas árvores distintas, em períodos distintos do ano (março/2009 e julho/2009), assegurando que os resultados obtidos para cada tratamento não sofressem influência da diferença das árvores ou da variação climática.

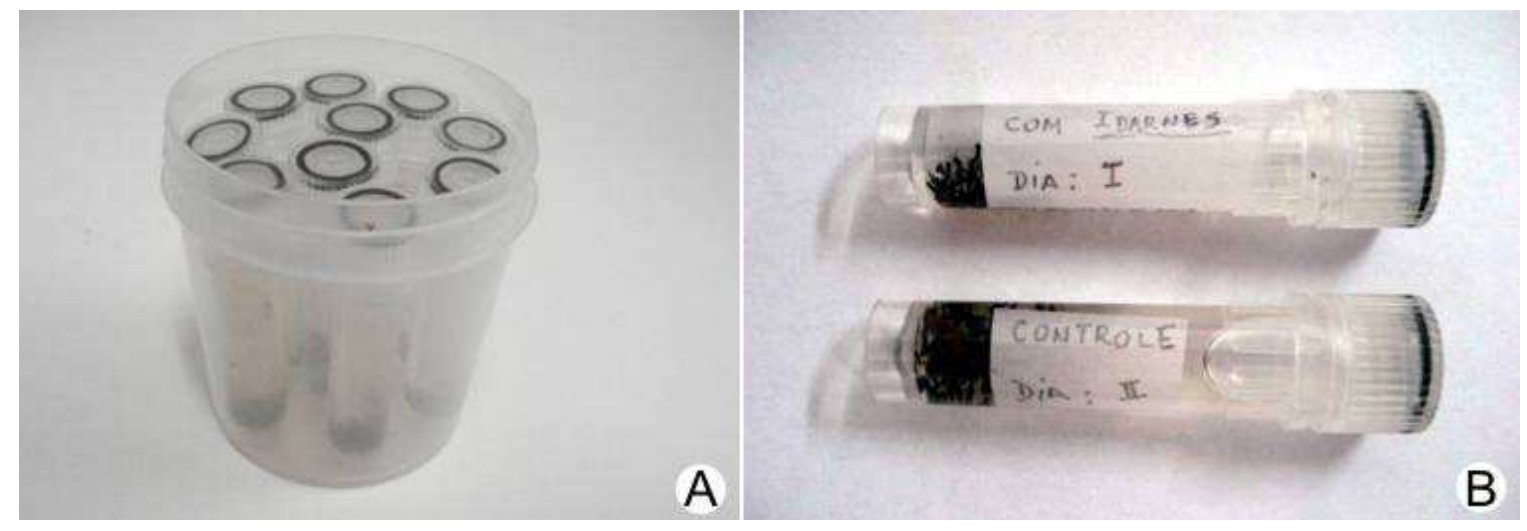

Figura 6. (A) Vespas nascidas dos experimentos de Sucesso da Visitação conservadas em álcool 70\%. (B) Recipientes individuais devidamente identificados.

\section{Análise dos dados}

A duração da receptividade foi estimada pelo número de dias em que se detectou atividade enzimática nos estigmas. Como não houve, em geral, diferença na duração da receptividade nos tratamentos com e sem vespas galhadoras, não foram utilizados testes formais de hipóteses. 
O comportamento das vespas polinizadoras durante o período de atratividade foi avaliada graficamente por meio de diagramas de linhas. A duração da atratividade nos dois tratamentos (com e sem galhadoras) foi avaliada por meio modelo linear (ANOVA), utilizando-se o programa estatístico R ( $\mathrm{R}$ Development Core Team). A análise foi realizada no conjunto completo de dados (das três repetições do experimento) e a variável "árvore" foi incluída no modelo como covariável para controlar estatisticamente as diferenças entre plantas/épocas estudadas.

O sucesso de visitação foi analisado graficamente, comparando-se os números de sementes, vespas e bexigas produzidos nos figos dos dois tratamentos (com e sem galhadores) colonizados ao longo do período receptivo. 
Resultados 
Receptividade do estigma

A duração da receptividade dos estigmas variou de sete a 10 dias. A oviposição de vespas galhadoras não alterou a duração da receptividade (Tabela 3). A colonização de Idarnes foi confirmada pela observação das fêmeas ovipondo e pelo início de formação de galhas nos figos desse tratamento (Figura 7).

Tabela 3. Duração da receptividade do estigma em dias, na presença e na ausência de vespas galhadoras.

\begin{tabular}{lcc}
\hline \multirow{2}{*}{ Árvore } & \multicolumn{2}{c}{ Duração da receptividade (dias) } \\
\cline { 2 - 3 } & Controle & Idarnes \\
\hline $1-\mathrm{fev} / 2008$ & 7 & 7 \\
$2-\mathrm{mar} / 2008$ & 9 & 10 \\
$3-\mathrm{jun} / 2009$ & 10 & 10 \\
\hline
\end{tabular}




\section{A}

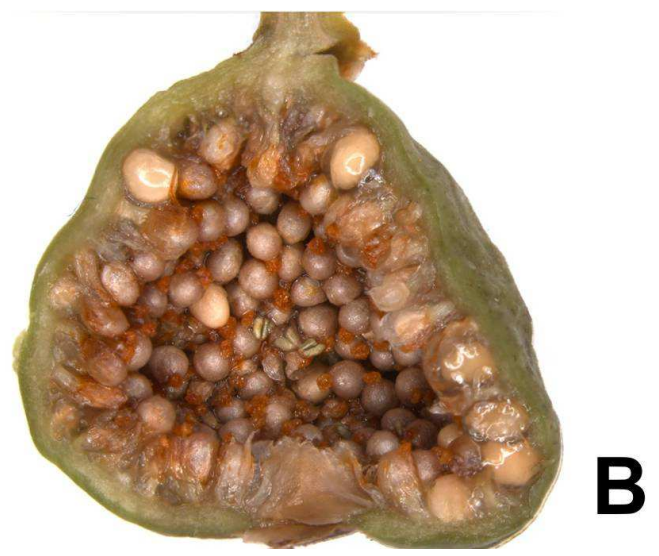

Figura 7. (A) fêmeas de Idarnes grupo flavicollis introduzidas sobre os figos ensacados; (B) presença de galhas em figo abortado.

Atratividade dos figos

A duração da atratividade dos figos variou de oito a nove dias e a oviposição de vespas galhadoras não alterou significativamente o período de atratividade $\left(\mathrm{F}_{5,160}=1,48 ; \mathrm{P}=\right.$ 0,198; Tabela 2).

Tabela 2. Duração da atratividade dos figos em dias (média \pm DP), na presença e na ausência de vespas galhadoras. Tamanho amostral (número de figos) indicado entre parênteses.

\begin{tabular}{lcc}
\hline \multirow{2}{*}{ Árvore } & \multicolumn{2}{c}{ Duração da atratividade em dias (média \pm DP) } \\
\cline { 2 - 3 } & $6,93 \pm 1,43(28)$ & Idarnes \\
\hline $1-$ fev/2009 & $6,96 \pm 1,25(28)$ \\
$2-\operatorname{mar} / 2009$ & $6,35 \pm 0,87(28)$ & $6,45 \pm 1,02(29)$ \\
$3-$ jun/2009 & & $6,44 \pm 1,12(27)$ \\
\hline
\end{tabular}


O comportamento das vespas polinizadoras mudou ao longo do período de atratividade dos figos. No entanto, não foi observada diferença entre o comportamento das vespas nos figos do tratamento controle e nos expostos às vespas Idarnes. No início do período atrativo, em ambos os tratamentos, as vespas apresentaram comportamento característico de reconhecimento dos voláteis relacionados à atração das vespas polinizadoras (Khandari et al., 1995), que consistiu em tocar o figo continuamente com as antenas, posicionar as asas junto ao corpo e localizar o ostíolo em até 240 segundos (Figura 9A-B). A partir do sexto dia de atratividade, esse comportamento foi menos intenso e as vespas tocavam o figo com as antenas em intervalos maiores (1 a 2 segundos; Figura 9CD). Gradativamente o comportamento de localização do ostíolo foi sendo menos frequente e as vespas não tocavam o figo com as antenas, batiam as asas esporadicamente até abandonar o figo, caminhando pelo pecíolo ou alçando voo (Figura 9E-F). 

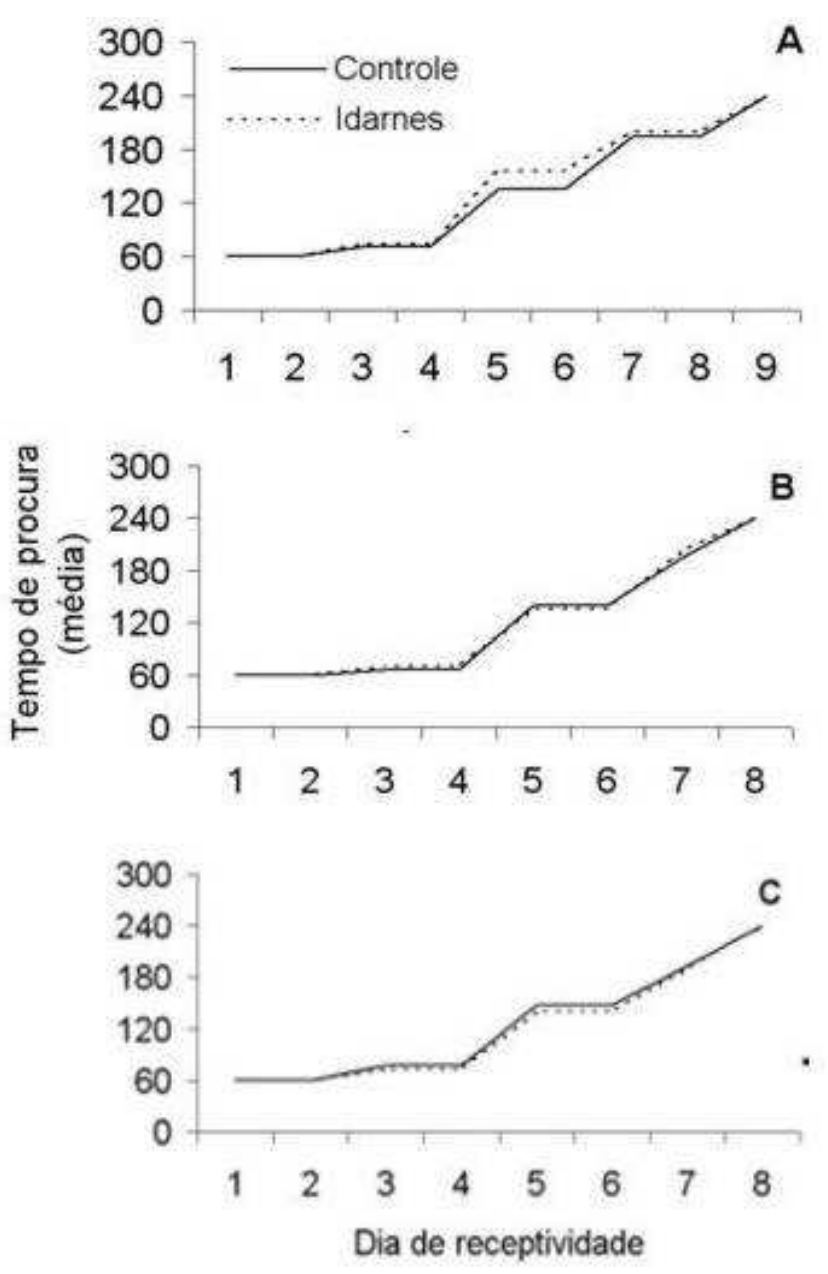

Figura 8. Comparação entre o tempo de procura (média) pelo ostíolo durante o período atrativo, em figos sem oviposição de Idarnes (controle) e com oviposição de Idarnes (Idarnes). (A) Experimento 1; (B) Experimento 2; (C) Experimento 3. 

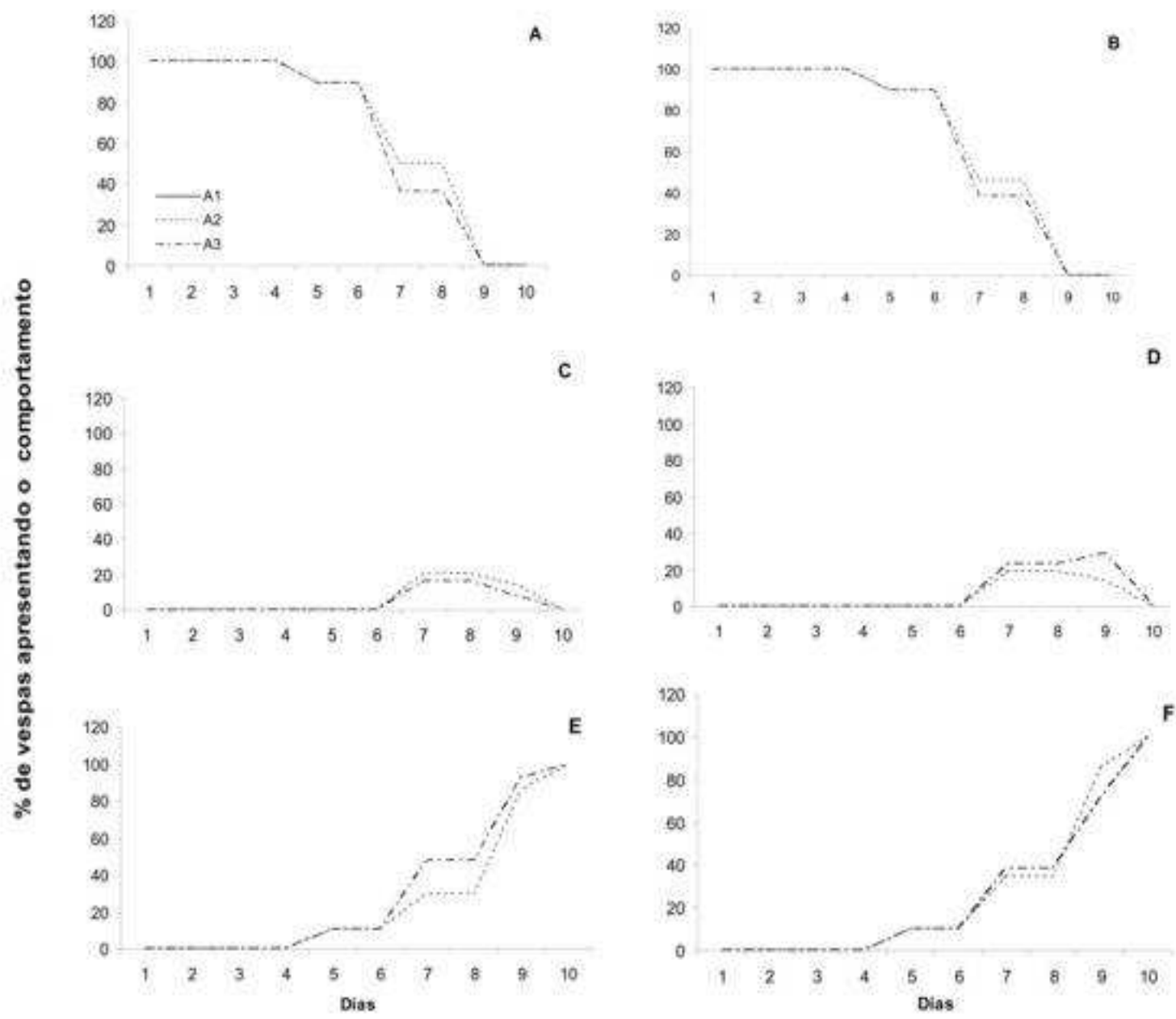

Figura 9. Comportamento das vespas ao longo do período atrativo."Antenas tocando o figo continuamente e apresentado asas juntas na ausência (A) e presença de galhadoras (B); Antenas tocando o figo com intervalos (1-2s) e asas juntas na ausência (C) e presença de galhadoras (D) e antenas não tocam o figo e bater de asas esporádica ou continuamente na ausência (E) e presença de galhadoras (F). Cada linha representa uma repetição (árvore) do experimento. $\mathrm{N}=30$ vespas/dia.

\section{Sucesso da visitação}

No primeiro experimento as proles de polinizadoras e de Idarnes foram maiores quando as fundadoras foram introduzidas entre o terceiro e o quinto dia de atratividade. A quantidade de bexigas no tratamento controle aumentou gradativamente, indicando que a mortalidade larval das polinizadoras aumentou ao longo do período receptivo. O efeito na produção de sementes foi variável ao longo do período receptivo, por motivos que não 
conseguimos identificar. Independentemente do dia de entrada da fundadora, a presença das vespas galhadoras parece ter reduzido o tamanho da prole de polinizadoras e aumentado a mortalidade larval nos figos (cerca de 10 vezes mais bexigas nos figos expostos às galhadoras - Figura 10).
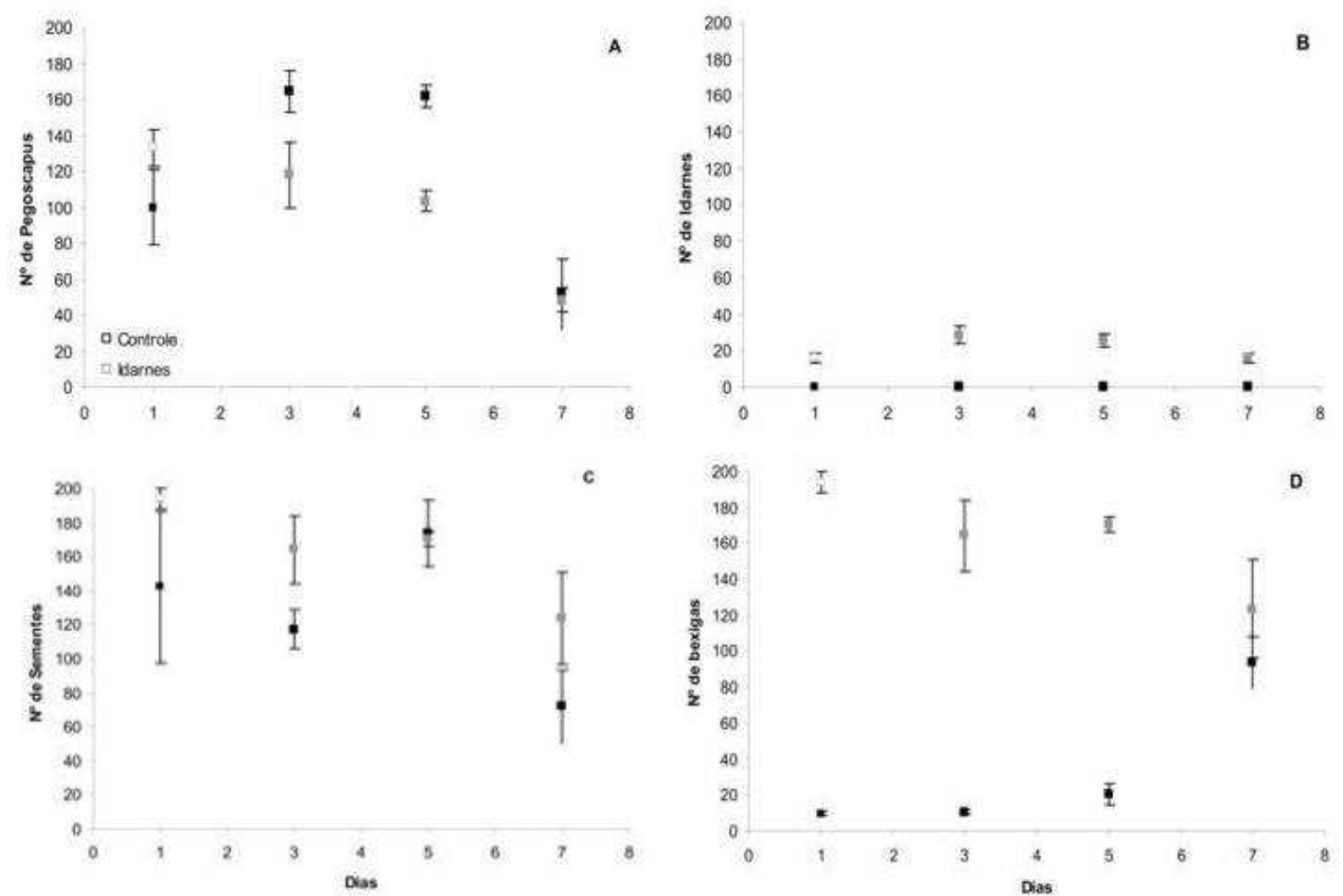

Figura 10. Proles de vespas, sementes e bexigas (média \pm erro-padrão) produzidas no primeiro experimento de sucesso de visitação (ver Materiais e métodos para detalhes). (A) Prole da polinizadora; (B) Prole de Idarnes; (C) Sementes; (D) Bexigas.

No tratamento controle do segundo experimento a prole das vespas polinizadoras foi maior quando as fundadoras foram introduzidas do terceiro ao sétimo dia após o início da receptividade. No entanto, com infestação maior de vespas galhadoras (cerca de quatro a cinco vezes maior que no primeiro experimento) (Figuras $10 \mathrm{~B}$ e 12B), o sucesso das polinizadoras é nulo a partir do quinto dia da receptividade. A partir do quinto dia as fundadoras não conseguiram penetrar os figos expostos às vespas Idarnes, pois o 
crescimento das galhas modificou a estrutura interna do figo, pressionando as brácteas do ostíolo (Figura 11B e 12). O número de bexigas para os dois tratamentos apresentou pouca variação e permaneceu reduzido ao longo de todo o período receptivo, devido ao insucesso das vespas polinizadoras a partir do quinto dia (Figura 12).

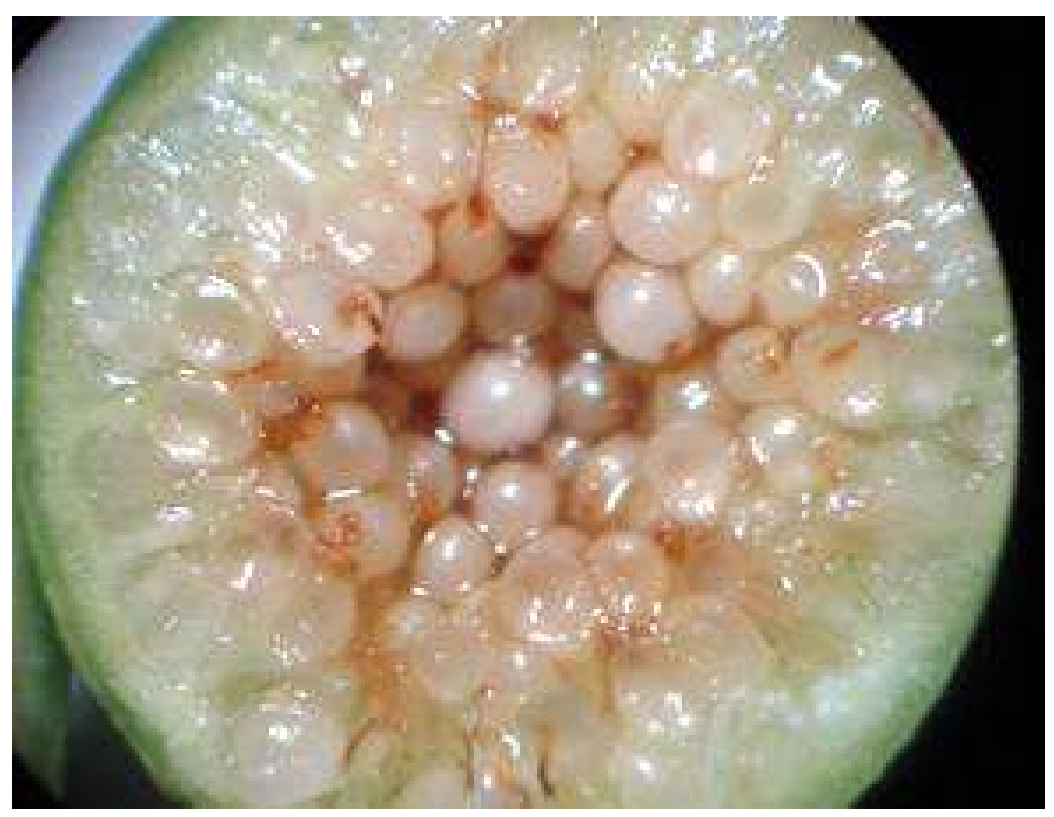

Figura 11. Galhas de vespas Idarnes grupo flavicollis no quinto dia após a oviposição (segundo experimento de sucesso de polinização), mostrando um preenchimento quase total do espaço do lúmen do figo. 

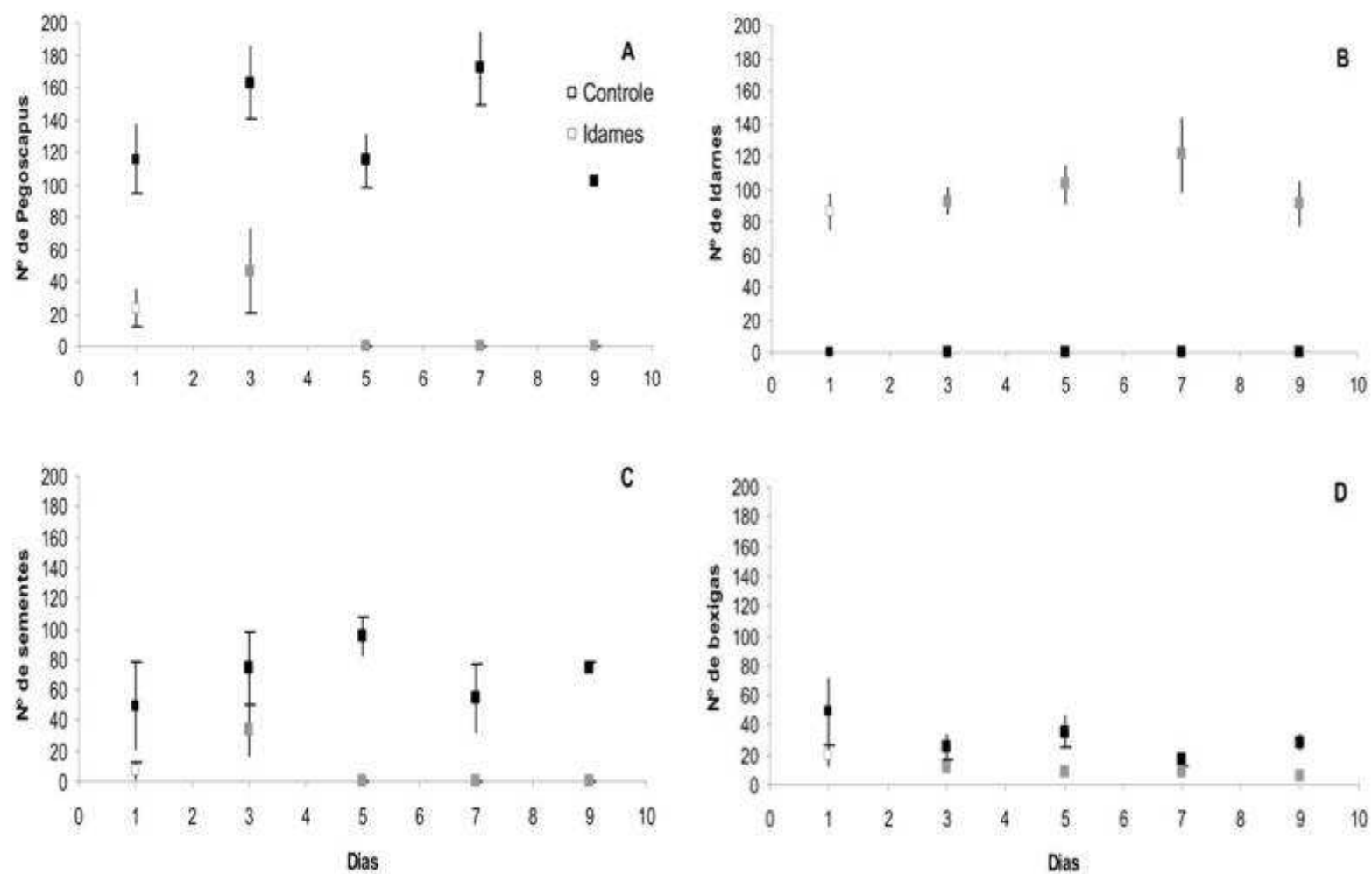

Figura 12. Proles de vespas, sementes e bexigas (média \pm erro-padrão) produzidas no segundo experimento de sucesso de visitação. (A) Prole da polinizadora; (B) Prole de Idarnes; (C) Sementes; (D) Bexigas. 
$\mathcal{D i s c u s s a ̃ o ~}$ 
O presente estudo indicou que a colonização por vespas galhadoras (Idarnes grupo flavicollis) não interfere na duração da receptividade e da atratividade dos figos de Ficus citrifolia. No entanto, em situação de maior infestação por vespas galhadoras, o sucesso das vespas polinizadoras é nulo a partir da metade do período receptivo. O insucesso está relacionado ao fechamento precoce do ostíolo devido ao pressionamento das brácteas do ostíolo pelo crescimento das galhas de Idarnes. Assim, nossos resultados sugerem que a alta infestação por vespas galhadoras pode encurtar a janela temporal na qual a colonização e polinização do figo são possíveis, interferindo negativamente nos componentes masculino (produção de vespas polinizadoras) e feminino (produção de sementes) das figueiras.

O efeito negativo das vespas galhadoras em $F$. citrifolia é potencialmente maior em ambientes perturbados, como áreas urbanizadas e paisagens com vegetação muito fragmentada. Nesses ambientes ocorrem altas densidades de árvores de $F$. citrifolia, uma vez que esta espécie apresenta estratégia pioneira de crescimento, ocupando preferencialmente bordas de matas e áreas abertas (R.A.S. Pereira \& L.F.M. Coelho, dados não publicados). A alta densidade de figueiras provavelmente favorece a manutenção da população local das vespas não-polinizadoras de figo, sendo freqüente a observação de super-infestações na natureza (Figura 13).

Um ponto importante no presente estudo foi que o efeito negativo das galhadoras foi causado pela modificação do espaço físico do figo. Não detectamos nenhum efeito forte relacionado ao desenvolvimento fisiológico das flores femininas (receptividade, atratividade e sucesso da colonização em infestação menor de galhadoras). Para interpretar esses resultados 
devem-se considerar as pressões seletivas que atuam ao longo da história evolutiva desse sistema.

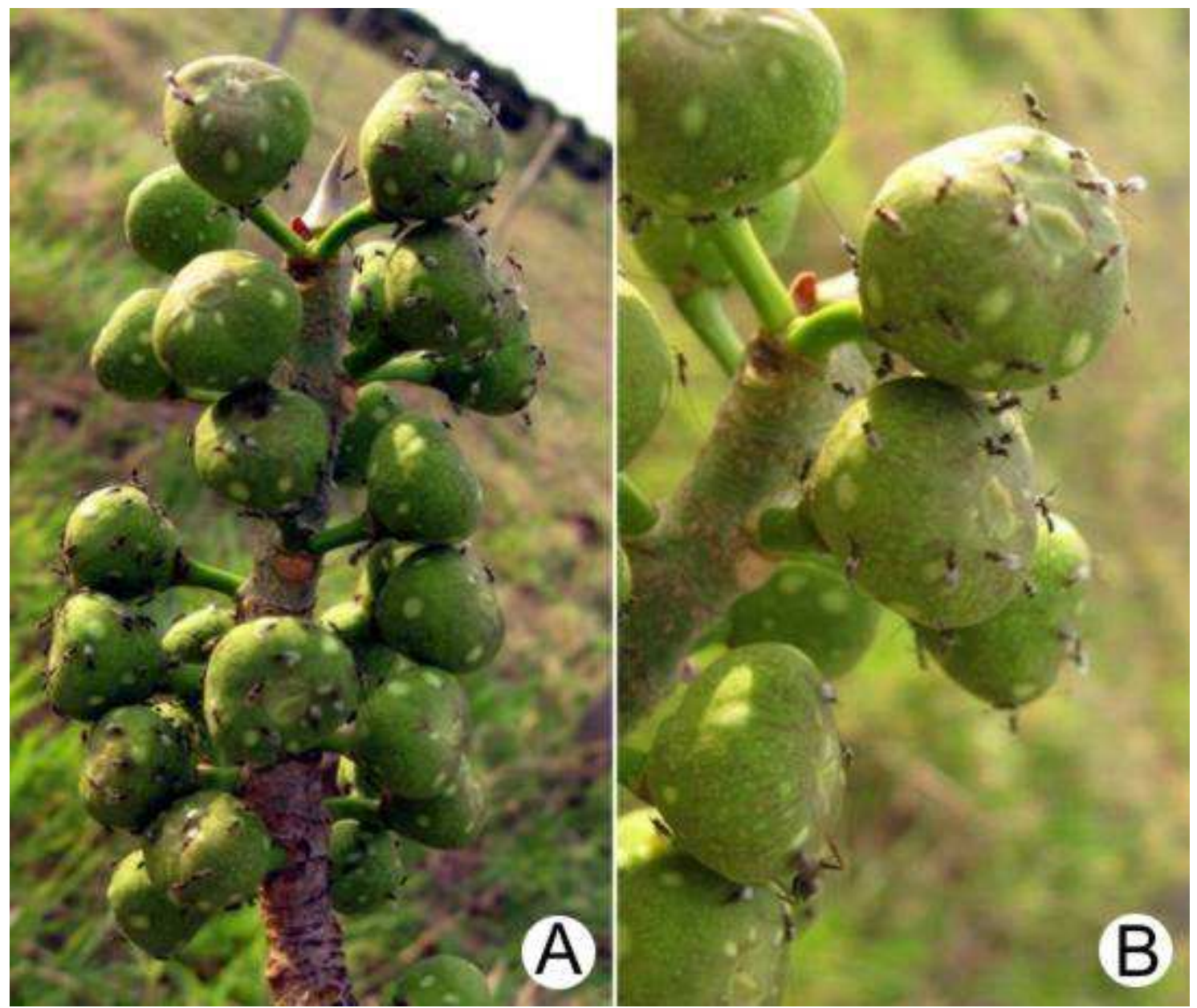

Figura 13. Figos com alta infestação de vespas Idarnes grupo flavicollis durante o período de receptividade em uma árvore de Ficus citrifolia localizada na borda de mata no Parque Estadual Morro do Diabo, Teodoro Sampaio/SP.

As vespas Idarnes do grupo flavicollis colonizam os figos antes ou durante a fase receptiva (Elias et al., 2008) e competem com as vespas polinizadoras por sítios de oviposição e alocação de recursos do figo (Kerdelhué \& Rasplus, 1996), mas não causam alteração nos períodos receptivo e atrativo dos sicônios. É provável que as vespas galhadoras sofram pressão seletiva para não interferir nos períodos de receptividade e 
atratividade dos figos, beneficiando-se dos serviços de polinização realizados pelas vespas polinizadoras. A diminuição dos períodos de atratividade e receptividade diminuiria as chances de o sicônio ser visitado por vespas polinizadoras, o que aumentaria as chances de morte da prole das vespas não-polinizadoras, seja por ficarem presas dentro do figo, pois em Idarnes, os machos são incapazes de abrir o orifício de saída, necessitando dos machos da espécie polinizadora para fazê-lo (Elias et al., 2008), ou ainda, pelo aborto espontâneo do mesmo (Bronstein, 1988). Por fim, a ausência de interferência das galhadoras não geraria pressão seletiva por parte da planta para a eliminação das não-polinizadoras, explicando a coexistência das duas espécies de vespas no sistema (Weiblen et al. 1995, Yu 2001).

Por outro lado, essas vespas galhadoras exercem um impacto negativo sobre a função masculina e, sob certas condições, também sobre a função feminina da planta, o que poderá, a longo prazo, causar uma desestabilização do mutualismo. A não-seleção contra as vespas parasitas pode, então, ser explicada de duas formas. Primeiro, caso apresentem infestação baixa e imprevisível, não haverá pressão seletiva contra elas, pois não afetariam o sucesso da planta. $\mathrm{O}$ impacto negativo na reprodução das figueiras deve ser bastante forte para superar o grande fluxo gênico dessas plantas, uma vez que fluxos gênicos amplos apresentam um efeito homogeneizante resistente a forças evolutivas. Segundo, porque, particularmente no grupo flavicollis, as vespas utilizam a mesma estratégia de oviposição usada pelas polinizadoras, inserindo seus ovipositores pelo estigma da flor e depositando seus ovos no nucelo do ovário (Elias, 2008; S. Jansen, dados não publicados). Assim, não é possível para a hospedeira evoluir mecanismo de eliminação seletiva, ou seja, a hospedeira não consegue remover essas vespas sem afetar as polinizadoras (Cook \& Rasplus, 2003).

O período atrativo de aproximadamente uma semana para $F$. citrifolia é pequeno quando comparado ao período de atratividade observado para outras espécies de Ficus, como F. 
pertusa, de três a quatro semanas (Bronstein, 1988; Anstett et al., 1996), F. carica, de duas a três semanas, e F. aurea, duas semanas (Khandari et al., 1995) (referido como receptivo), mas condizente com o curto período de desenvolvimento dos sicônios dessa espécie (35 dias em meses quentes e 101 dias em meses frios, em média) (Pereira et al., 2007). Já o período de receptividade, apesar de apresentar uma pequena variação ente as diferentes árvores, também encontrada em outras espécies de Ficus (Khandari et al., 1995), pode ser considerado de, aproximadamente, nove dias, também condizente com o curto período de desenvolvimento dos sicônios.

Hossaert-Mckey et al. (1994) observaram que os compostos voláteis emitidos pelo sicônio durante o período de atratividade são efetivos na estimulação do comportamento de entrada no figo e de oviposição por vespas que já tenham encontrado esse sicônio, e que ao final da fase receptiva, há um declínio na liberação desses voláteis. A observação do comportamento de entrada das vespas nos sicônios é, portanto, uma ferramenta confiável para a determinação do período de atratividade das flores. Hossaert-Mckey et al. (1994) afirmaram, também, que os figos só emitem compostos voláteis atrativos para os polinizadores durante o período de receptividade. No entanto, os resultados indicam que o período de receptividade é um pouco maior que o período de atratividade (cerca de $48 \mathrm{~h}$ ). Essa diferença sugere que os sicônios se tornam receptivos antes de estarem atrativos, ou seja, atratividade e receptividade estão estreitamente relacionadas, mas são eventos distintos, muitas vezes usados erroneamente como sinônimos na literatura (Bronstein \& Patel, 1992; Khandari et al., 1995).

A receptividade se refere às flores: quando se tornam maduras significa que estão receptivas, ou seja, estão aptas a receber pólen e ovos de vespas, permitindo seu desenvolvimento em sementes e na nova prole de vespas, respectivamente. A atratividade, por sua vez, se refere ao figo: quando está atrativo é capaz de atrair suas vespas relacionadas mesmo que se encontrem a grandes distâncias e desencadear o comportamento 
de entrada, através da liberação de compostos químicos voláteis. Ainda assim, a presença de vespas, tanto polinizadoras quanto não-polinizadoras nas árvores, durante o período de receptividade (Figura 13), reforça a idéia de que, mesmo não sendo equivalentes, há uma estreita relação entre o tempo de receptividade das flores e a atratividade dos sicônios.

O aumento na liberação de voláteis atrativos ocorre paralelamente ao aumento no diâmetro do figo (Barker, 1985) e diminui conforme o figo cresce muito (Patel et al., 1995). É provável que o pico de liberação de voláteis se dê concomitantemente ao período em que as flores pistiladas estejam em seu auge de receptividade. Essa relação deve aumentar as chances de haver polinização, uma vez que as vespas são atraídas para os figos quando suas flores pistiladas estão aptas a receber pólen (e ovos). A liberação dos compostos voláteis deve, então, sofrer uma abrupta redução ao final do período de receptividade (quando as flores já não estão mais em seu estado ótimo), como foi observado por Hossaert-McKey et al. (1994) em F. carica.

Os resultados obtidos nos experimentos de sucesso da visitação mostraram que o número de sementes, polinizadoras e Idarnes é maior quando a fundadora colonizou o figo entre o terceiro e o sétimo dia de receptividade. O menor sucesso no primeiro dia da receptividade provavelmente foi artefato experimental, pois a menor luminosidade dentro dos sacos de voil pode ter atrasado o desenvolvimento dos figos experimentais.

A redução na prole de polinizadoras ocorreu em todos os experimentos de sucesso da visitação. A redução na prole de polinizadoras se deve à competição direta entre as vespas (polinizadoras e galhadoras) pelas flores femininas que apresentam ovários mais próximos ao lúmen do figo (Pereira, 1998). West \& Herre (1994) e West et al. (1996) também observaram uma correlação significantemente negativa entre a presença de vespas Idarnes e a produção de vespas polinizadoras em outras cinco espécies de figueiras monoicas $(F$. bullenei, F. citrifolia, F. costaricana, F. obtusifolia, F. popenoei e F. trigonata). Kerdelhué 
e Rasplus (1996), por sua vez, observaram que as galhadoras têm um impacto significantemente negativo sobre a produção de sementes e polinizadoras em $F$. sur, e Kobi et al. (1996), que a abundância de vespas polinizadoras de F. microcarpa está negativamente correlacionada à abundância de Odontofroggatia galili, também galhadora (Elias, dados não publicados).

A interação Ficus - vespas de figo vem sendo moldada por seleção natural há pelo menos 60 milhões de anos (Lopez-Vaamonde et al., 2009). Nesse período, um ajuste fino entre o desenvolvimento embriológico da planta e o larval do inseto foi selecionado (Elias, 2008; Jansen, 2009; Kjellberg et al., 2005). Assim, a ocorrência do impacto negativo da alta infestação de vespas galhadoras, demonstrado nesse trabalho, parece ser recente na história evolutiva desse grupo. As condições naturais nas quais o mutualismo evoluiu foi drasticamente modificado no último século, devido ao desmatamento e à ocupação humana nessas áreas. Desta foram, é impossível prever as consequências, a longo prazo, da presença destas galhadoras na estabilidade do mutualismo e, consequentemente, na cadeia de animais associados às figueiras. 
Considerações finais

45 
O presente estudo ajudou a compreender melhor o papel das vespas galhadoras no mutualismo Ficus - vespas de figo. Toda interação mutualística é passível de invasão por espécies “parasitas”, que exploram os recursos resultantes dessa associação (Yu, 2001). No caso do gênero Idarnes, as vespas do grupo flavicollis exploram os ovários das flores pistiladas para desenvolvimento de suas proles. A formação de galhas em ovários das flores de Ficus resulta de um ajuste fino e sincronizado entre o desenvolvimento embriológico da planta e da larva do inseto (Jansen, 2009). Assim, espera-se que a exploração das flores por vespas galhadoras não-polinizadoras sofra forte restrição imposta pelo mutualismo. A janela temporal disponível para colonização seria limitada de um lado pelo desenvolvimento da flor (o ovário deve estar maduro o suficiente para que a galha se desenvolva) e de outro pela competição com as vespas polinizadoras (o número de ovários disponíveis diminui ao longo do tempo). Essas restrições exerceriam pressão seletiva contra qualquer alteração no processo de polinização das figueiras, uma vez que o sucesso das galhadoras depende do sucesso das polinizadoras. De fato, nosso estudo demonstrou que a duração da receptividade do estigma e a atratividade do figo não se alteram com a colonização por vespas galhadoras. Outros estudos mostram que essas vespas adotam estratégia de oviposição muito semelhante à das vespas polinizadoras, inserindo o ovipositor através do estigma da flor (Elias, 2008) e depositando o ovo na mesma porção do ovário utilizado pelas vespas polinizadoras (S. Jansen, dados não publicados).

Os resultados aqui apresentados são relevantes para compreender que adaptações tão especializadas são moldadas na natureza. O gênero Idarnes foi escolhido por apresentar espécies que adotaram estratégias diferentes de exploração do mutualismo. Esse gênero 
possui três linhagens (grupos incerta, flavicollis e carme) que seguiram caminhos evolutivos diferentes. As vespas do grupo incerta colonizam os figos em início de desenvolvimento e galham a parede da inflorescência. Nessa fase, as flores pistiladas estão imaturas, assim, a utilização da parede parece ter sido selecionada por não interferir no sucesso futuro da polinização. As vespas do grupo flavicollis colonizam na sequência, quando as flores pistiladas estão maduras. Nessa fase, as pressões seletivas moldaram um modo de oviposição complexo e semelhante ao adotado pela espécie polinizadora. As vespas do grupo carme colonizam o figo tardiamente e exploram galhas ou sementes em desenvolvimento (Pereira et al., 2007). A comparação dessas três linhagens de vespas esclarece como diferentes soluções evolutivas são "encontradas" para solucionar o mesmo problema (explorar os recursos do mutualismo).

Por fim, esse trabalho mostra, de forma surpreendente, como estudos extremamente específicos podem ser transcendidos para a análise da ação antrópica na evolução das espécies. O mutualismo Ficus - vespas de figo evoluiu, provavelmente, em um cenário onde as figueiras ocorriam em baixa densidade e com pouca infestação por vespas nãopolinizadoras, como observado em florestas bem preservadas. No entanto, no último século, intervalo de tempo desprezível na escala evolutiva, esse cenário foi drasticamente alterado pela redução de hábitat e aumento das áreas de borda de mata. Nessa nova condição, as espécies heliófitas, como $F$. citrifolia, tiveram suas populações aumentadas nas áreas antropizadas, favorecendo preferencialmente as populações das espécies nãopolinizadoras e levando, consequentemente, a superinfestações. Como demonstrado aqui, o aumento da importância das vespas não-polinizadoras pode anular o sucesso reprodutivo das figueiras, impedindo a colonização pelas polinizadoras. A mensagem final é que as figueiras evoluíram sob certas circunstâncias e no instante atual, devido à ação antrópica, estão sofrendo pressões nunca experimentadas. O resultado disso no futuro do mutualismo, 
e de todas as outras interações envolvendo as figueiras, é absolutamente impossível de se prever. 
Referências Bibliográficas

49 
Abdurahiman, U.C. \& Joseph, K.J. 1978. Cleptoparasitism of the fig wasps (Torymidae: Chalcidoidea) in Ficus hispida L. Entomon 3: 181-186

Anstett, M. C.; Kjellberg, F. \& Bronstein, J. L. 1996. Waiting for wasps: consequences for the pollination dynamics of Ficus pertusa L. Journal of Biogeography 23: 459- 466.

Barker, N. P. 1985. Evidence of a volatile attractant in Ficus ingens (Moraceae). Bothalia $15: 607-611$.

Begon, M.; Harper, J.L. \& Townsend, C.R. 1996. Ecology: individuals, population and communities. Blackwell Science, Oxford

Berg, C.C. 1989. Classification and distribution of Ficus. Experientia 45:605-611

Bronstein, J. L. 1988. Limits to fruit production in a monoecious fig: Consequences of an obligate mutualism. Ecology 69: 207-214.

Bronstein, J. L. 1992. Seed predator as mutualists: Ecology and evolution of the fig pollinator interaction, p. 1-43. In: Bernays, E. (ed.), Insect-Plant Interactions. CRC Press, Boca Raton.

Bronstein, J. L. \& Patel, A. 1992. Causes and consequences of within-tree phonological patterns in the Florida Strangling Fig, Ficus aurea (Moraceae). American Jounal of Botany $79(1): 41-48$.

Carauta, J.P.P. 1989. Ficus (Moraceae) no Brasil: conservação e taxonomia. Albertoa 2:1-365.

Cerezini, M. T.; Gobbo, S. E.; Pereira, R. A. S. Comunidade de figueiras do campus da USPRibeirão Preto: possíveis implicações na manutenção da fauna de frugívoros e na recomposição de áreas de preservação permanente. In: VII Congresso de Ecologia do Brasil, 2005, Caxambu. Anais do VII Congresso de Ecologia do Brasil, 2005. 
Cook, J. M. and Rasplus, J. Y. 2003. Mutualists with attitude: coevolving fig wasps and figs. Trends Ecol.\& Evol. 18 (5):241-248.

Dafni, A. and Maués, M.M. 1998. A rapid and simple procedure to determine stigma receptivity. Sex. Plant Reprod. 11: 177-180.

Elias, L. G. 2008. Estratégias de utilização de recursos em vespas parasitas do mutualismo figueiras - vespas de figo. Dissertação de mestrado. Universidade de São Paulo, Ribeirão Preto.

Elias, L. G.; Menezes Jr., A. O. \& Pereira, R. A. S. 2008. Colonization sequence of nonpollinating fig wasp associated with Ficus citrifolia in Brazil. Symbiosis 45: 107-111.

Galil, J. \& Eisikowitch, D. 1968. On the pollination ecology of Ficus sycomorus in east Africa. Ecology 49: 259-269

Hossaert-McKey, M.; Gibernau, M. \& Frey, J.E. 1994. Chemosensory attraction of fig wasps to substances produced by receptive figs. Entomol. Exp. Appl.70: 185-191.

Jansen, S. G. 2009. Biologia larval de Pegoscapus tonduzi (Chalcidoidea:Agaonidae), polinizador de Ficus citrifolia. Dissertação de mestrado. Universidade de São Paulo, Ribeirão Preto.

Kerdelhué, C. \& Rasplus, J. Y. 1996. Non-pollinating Afrotropical fig wasps affect the figpollinator mutualism in Ficus within the subgenus Sycomorus. OIKOS 75:3-14.

Khadari, B.; Gibernau, M.; Anstett, M. C.; Kjellberg, F. \& Hossaert-McKey, M. 1995. When figs wait for pollinators: the length of fig receptivity. Am. J. Bot. 82(8):992-999.

Kjellberg, F., Jousselin, E., Hossaert-Mckey, M. and Rasplus, J.Y. 2005. Biology, Ecology and Evolution of Fig-pollinating Wasps (Chalcidoidea, Agaonidae). In: Biology, Ecology and Evolution of Gall-Inducing Arthropods. eds. Raman, A., Schaefer, C.W. and Withers, T.M. Science publishers, Inc., New Hampshire, pp. 539-571. 
Kobi, M.; Chaleb, M.; Edelin, C. \& Michaloud, G. 1996. Relationship between a mutualist and a parasite of the laurel fig, Ficus microcarpa L. Can. J. Zool. 74: 1831-1833.

Lopez-Vaamonde, C.; Niklas Wikström, N.; Kjer, K.M.; Weiblen, G.D.; Rasplus, J.Y; Machado, C.A.; Cook, J.M. 2009. Molecular dating and biogeography of figpollinating wasps. Molecular Phylogenetics and Evolution 52: 715-726.

Patel, A.; Anstett, M-C.; Hossaert-McKey \& Kjelberg, F. 1995. Pollinators entering female dioecious figs: why commit suicide? J. Evol. Biol. 8:301-313.

Pereira, R. A. S. 1998. Relação do desenvolvimento de vespas do figo (Hymenoptera: Chalcidoidea) com aspectos reprodutivos de Ficus eximia Schott (Moraceae). Dissertação de mestrado. Universidade Estadual de Campinas, Campinas.

Pereira, R. A. S.; Semir, J. \& Menezes, A. O. 2000. Pollination and other biotic interactions in figs of Ficus eximia Schott (Moraceae). Braz. J. Bot. 23:217-224.

Pereira, R. A. S. 2002. Competição local por acasalamento em vespas de figo (Hymenoptera: Chalcidoidea) associadas a Ficus eximia Schott (Moraceae). Tese de Doutorado. Universidade Estadual de Campinas, Campinas.

Pereira, R. A. S.; Rodrigues, E. \& Menezes Jr., A. O. 2007. Phenological patterns of Ficus citrifolia (Moraceae) in a seasonal humid-subtropical region in Southern Brazil. Plant Ecol. 188: $265-275$.

Shanahan, M.; So, S.; Compton, S. G. \& Corlett, R. T. 2001. Fig-eating by vertebrate frugivores: a global review. Biol.Rev. 76:529-572.

Verkerke, W. 1989. Structure and function of the fig. Experientia 45:612-622.

Ware, A. B. \& Compton, S. G. 1994. Responses of fig wasps to host plant volatile cues. Journal of Chemical Ecology 20(3): 785-802.

Weiblen, G.D. 2002. How to be a fig wasp. Annu. Rev. Entomol. 47: 299-330. 
Weiblen, G.D.; Flick B. \& Spencer H. 1995. Seed set and wasp predation in dioecious Ficus variegata from an Australian wet tropical forest. Biotropica 27: 391-394.

West, S. A. \& Herre, E. A. 1994. The ecology of the New World fig-paratising wasps Idarnes and implications for the evolution of the fig-pollinator mutualism. Proc. R. Soc. Lond. B 258:67-72.

West, S. A.; Herre, E. A.; Windsor, D. M. \& Green, P. R. S. 1996. The ecology and evolution of the New World non-pollinating fig wasp communities. Journal of Biogeography 23:447458.

Yu, D. W. 2001. Parasites of mutualisms. Bio. J. Linnean Soc. 72:529546.

Zhen, W.Q; Huang, D.W.; Xiao, J.H.; Yang, D.R.; Zhu, C.D \& Xiao, H. 2005. Ovipositor lenght of three Apocrypta species: effect on oviposition behavior and correlation with syconial thickness. Phytoparasitica 33: 113-120. 